\title{
The Ethics of Appropriate Justice Approaches: Lessons From a Restorative Response to Institutional Abuse
}

\begin{abstract}
Alikki Vernon
The justice system and the practice of dispute resolution and conflict handling have co-evolved in recent decades. Practitioners face challenges that raise questions about (i) the justice system as a whole, and (ii) the range of processes currently available for resolving disputes and conflicts. These broader questions should be addressed by alternative dispute resolution practitioners, and by the designers and administrators of systems for appropriate dispute and conflict resolution. There have recently been several major initiatives in Australia in response to institutional abuse and sexual offending. This paper explores one of these initiatives: the Defence Abuse Response Taskforce. The Taskforce was established to address institutional abuse and sexual offending in the Australian Defence Force. It raised a number of important ethical questions and offers valuable lessons about appropriate justice approaches in complex matters.
\end{abstract}

\section{INTRODUCTION}

In recent decades, new paradigms of justice have emerged in Australia's justice system. ${ }^{1}$ The practice of appropriate dispute resolution (ADR) and conflict handling has likewise evolved. ADR, and the related areas of therapeutic jurisprudence and restorative practices are gradually transforming the justice system. The parameters of this transformation extend beyond the formal legal system to the governance of schools and workplace industrial relations, and the services provided by government agencies, dispute settlement centres and community organisations.

An increasingly nuanced approach to dispute resolution and conflict management includes more sophisticated case management. There is a trend for presenting issues to be analysed more carefully, and for a larger range of resolution processes to be available. More than one process may

1 Michael King, Arie Freiberg, Becky Batagol and Ross Hyams, Non-Adversarial Justice (Federation Press, 2009) 1-6. Changes in the justice landscape include: new jurisdictions oriented towards problem-solving; the greater use of case management and a more interactive role for judges, lawyers and clients in court (in Court Integrated Services Programs); greater partnerships between professional groups such as legal, health and correctional personnel and the establishment of mediation, conciliation and restorative justice programs in civil and criminal jurisdictions. 
be used for the one case. ${ }^{2}$ Dispute resolution mechanisms such as litigation and mediation are not necessarily seen as mutually exclusive but rather, as different strategies to address the same dispute at different stages. $^{3}$ This has been a valuable lesson learnt by the profession. The question 'Which process option is most likely to produce an appropriate and fair resolution of the presenting issues?' is becoming central for ADR and conflict management practitioners.

A related lesson is that the ADR profession can help re/design and improve systems for appropriate dispute and conflict resolution and management. This work raises broad ethical questions about the link between procedural and substantive justice: 'What are fair rules?'; 'How can we ensure fair play?' and 'How can we generate fair outcomes?' Neither individual ADR/conflict management practitioners, nor the judiciary, should be solely responsible for answering these questions. ${ }^{4}$ They need to be addressed (i) across the broader justice system, and they need to be asked of (ii) policy developers and program administrators, who make available certain processes in the search for appropriate, effective and fair resolutions. By asking broad ethical questions, individual practitioners and program administrators, can help ensure appropriate justice.

This considered approach has guided recent efforts to respond to institutional abuse and sexual offending in Australia. Legal, health and human service agencies are all responsible for providing constructive 'justice mechanisms. . 'Integrated interventions' and practice frameworks have been developed to guide responses to institutional abuse, sexual

2 See Victorian Public Sector Commission, Developing Conflict Resilient Workplaces: A Report for Victorian Public Sector (March 2005) <vpsc.vic.gov.au/wp-content/ pdf-download.php?postID=9081>; Joe Harman, 'From Alternative to Primary Dispute Resolutions: The Pivotal Role of Mediation in (and in avoiding) Litigation' (Paper presented at National Mediation Conference, Melbourne, 2014).

3 Harman, above n 2; see also Bathurst CJ, 'The Role of the Courts in the Changing Dispute Resolution Landscape' (2012) 35(3) University of New South Wales Law Journal 870, 877.

4 The author is indebted to Dr David Moore who provided feedback and resources for this article. David Moore is the President of the Victorian Association of Restorative Justice, an expert facilitator, and trainer for (i) Victoria's Youth Justice Group Conferencing program, and (ii) the Defence Abuse Response Taskforce (DART) program, and similar restorative programs around Australia and internationally. The questions raised here, and the distinctions made between principles, program and process, are outlined in David Moore, 'Managing Social Conflict: The Evolution of a Practical Theory' (2004) 31(1) Journal of Sociology and Social Welfare 71-91.

$5 \quad$ Kathleen Daly, 'What Is Restorative Justice? Fresh Answers to a Vexed Question, Victims \& Offenders (2015) 11 An International Journal of Evidence-based Research, Policy, and Practice 9. Daly defines (at 18) a justice mechanism as 'a justice response, process, activity, measure, or practice ... residing on a continuum from conventional to innovative'. Conventional mechanisms are described as standard approaches to criminal prosecution, trial, sentencing, and post-sentence, advocacy and the like, whereas innovative mechanism are ADR processes, group conferencing, problem-oriented courts, and circles of support. Such justice mechanisms are not mutually exclusive, and can be considered a part of an effective strategy in dealing with one case or a category of case types. 
offending and family violence. ${ }^{6}$ The current justice system fails to meet many of the justice needs of survivors. ${ }^{7}$ There is evidence that punitive interventions, and further reform to both criminal and civil litigation, may not alone produce optimal results. An appropriate mix of interventions can supplement current legal system responses and more effectively deter harmful behaviour, provide reparation where harm does occur, and address individual needs. ${ }^{8}$

6 Royal Commission into Institutional Responses to Child Sexual Abuse, 'Consultation Paper: Redress and Civil Litigation' (Media Release 30 January 2015) <childabuseroyalcommission.gov.au/getattachment/b50aac23-5224-4cc189c1-cfa36ad743a0/Consultation-paper-Redress-and-civil-litigation>; Justice Peter McClellan, 'Chair, Royal Commission into Institutional Responses to Child Sexual Abuse: Statement on Redress and Civil Litigation' (Media Release 30 January, 2015) <childabuseroyalcommission.gov.au/media-centre/ speeches/redress-and-civil-litigation $>$ See also Heather Strang, Restorative Justice Programs in Australia: A Report to the Criminology Research Council (Criminology Research Council, March 2001) <criminologyresearchcouncil. gov.au/reports/strang/report.pdf >; Australian Institute of Criminology, 'Restorative Justice in Australia' Media Release, 2014) <www.aic.gov.au/ publications/current\%20series/rpp/121-140/rpp127/05_restorative.html>; Centre for Innovative Justice, 'Innovative Justice Responses to Sexual Offending- Pathways to Better Outcomes for Victims, Offenders and the Community' (Media Release, May 2014) $16<$ mams.rmit.edu.au/qt1g6twlv0q3. pdf>; Tracy Cussen and Matthew Lyneham, ACT Family Violence Intervention Program review (Australian Institute of Criminology, 2012) <www.aic.gov. au/media_library/publications/tbp/tbp052/tbp052.pdf >; Carolyn Hoyle and Nicola Palmer, 'Family justice centres: A model for empowerment?' (2014) 20 (1) International Review of Victimology 191, 206-207; Department of Social Services, 'Second Action Plan 2013-2016 - Moving Ahead - of the National Plan to Reduce Violence against Women and their Children 2010-2022' (Media Release, June 2014), 27 <www.dss.gov.au/sites/default/files/documents/09_2014/ dss012_14_book_tagged_reduced.pdf $>$.

7 State of Victoria, Royal Commission in Family Violence: Summary and Recommendations, Parliamentary Paper No 132 (2016) 38; Kathleen Daly, 'Conventional and Innovative Justice Responses to Sexual Violence'( 2011) 12 ACSSA Issues Australian Centre for the Study of Sexual Assault 1; Centre for Innovative Justice, above n 6, 34; Janet Phillips and Penny Vandenbrock, 'Domestic, Family, Sexual Violence in Australia: An Overview of the Issues' (Research Paper Series 2014-15, Parliamentary Library, Parliament of Australia, 2014) 13-14; Report for the Royal Commission into Institutional Responses to Child Sexual Abuse, Jane Bolitho and Karen Freeman, The Use and Effectiveness of Restorative Justice in Criminal Justice Systems Following Child Sexual Abuse or Comparable Harms (March, 2016); Carolyn Neilson and Bonnie Renou, Will somebody listen to me? Insights, actions and hope for women experiencing family violence in regional Victoria (Summary Report, Loddon Campaspe Legal Centre, 2015) <lcclc.org.au/wp-content/uploads/2015/05/ FV_FULL_online_v2.pdf>.

8 Jeff Foote et al, Selecting Interventions to Reduce Family Violence and Child Abuse in New Zealand - A report to The Glenn Inquiry (Institute of Environmental Science and Research Limited, September 2014) <www.noviolence.com.au/sites/default/files/reportfiles/selectinginterventions.pdf $>$; Royal Commission into Family Violence: Summary and Recommendations, above n 7, 1. 
Many victims of abuse and family violence are seeking an approach that gives them a voice, validates their experience, vindicates their claims, and provides accountability for perpetrators and/or institutions. ${ }^{9}$ The conventional justice system provides important but limited options. Two recent Royal Commissions in Australia have examined institutional responses to child sexual abuse (a Commonwealth Commission) and family violence (a Victorian Commission) have proposed examples of what victims are seeking. Commissioners have outlined problems experienced by survivors of abuse and family violence with the current redress schemes, civil litigation and/or criminal prosecution. The Commissioners have highlighted a 'pressing need' to provide avenues through which survivors can obtain appropriate redress for past abuse, to reform the conventional justice system in order to more effectively deal with existing problems, and to minimise the occurrence of future abuse or violence. Consultation Paper 7 from the Royal Commission into Institutional Responses to Child Sexual Abuse identifies a number of possible institutional responses for appropriate redress' for survivors. ${ }^{10}$ The Victorian Royal Commission into Family Violence recommended short, medium and long-term systemic improvements to Victoria's response to family violence. These improvements seek to reduce the incidence of family violence, hold perpetrators to account, and support victims. ${ }^{11}$

The recommendations of the Victorian Royal Commission aim to prevent and respond to family violence by improving policy, coordinating community and government responses, and designing and implementing services that operate in partnership with those who work directly with individuals and families affected by family violence, and have expertise in a range of relevant disciplines. ${ }^{12}$ The Commission recommends essential reforms to the court system, and also the development of a restorative justice approach 'to meet a broad range of victims' needs that might not always be met through the courts and to help victims recover from the impact of the abuse they have suffered'. ${ }^{13}$ A restorative justice process is an 'additional option for (not a substitute or precondition for) pursuing action through the courts'.

A number of recent studies, reviews, reports and recommendations propose that restorative responses may be appropriate to address certain cases of institutional abuse, sexual abuse and family violence. ${ }^{14}$ A core

$9 \quad$ Kathleen Daly, 'A Tale of Two Studies: Restorative Justice from a Victim's Perspective' in Elizabeth Elliott and Robert Gordon (eds), New Directions in Restorative Justice (Routledge, 2011) 153, 153. See also Daly, 'Conventional and Innovative Justice Responses to Sexual Violence', above n 7, 25.

10 Royal Commission into Institutional Responses to Child Sexual Abuse, above n 6.

11 Royal Commission into Family Violence, above n 7. See also Loddon Campaspe Community Legal Centre, Victorian Family Violence Royal Commission Commences (10 March 2015) <lcclc.org.au/2015/03/family-violence-rc/>.

12 Royal Commission into Family Violence, above n 7, 3.

13 Ibid 38.

14 See the literature review presented in the Australian Institute of Criminology Reports, Restorative Justice in Australian Criminal Justice System, AIC Report 
principle of restorative practices is to work with individuals and communities, to deter harmful behaviour, maintain social order and promote wellbeing by 'restoring right relations' and by 'ending harmful relations' ${ }^{15}$ This approach seeks to 'enhanc[e] the justice quality of the relations and transactions in which people are engaged'. ${ }^{16}$

A key element of successful restorative justice programs has been the availability of skilled support and mentoring for convenors. A culture of reflective practice is crucial. Knowledge and skills need to be shared, and this practice needs to be supported and maintained through formal policies and processes. ${ }^{17}$ Conversely, restorative justice programs have failed to flourish where: (i) it has been assumed that professionals competent in related work can simply attend a basic restorative group conferencing training session and move quickly to an adequate standard of facilitation; and (ii) support and mentoring to reinforce best practice have not been provided.

No 127 (2014). This review builds on the report of T Cussen and M Lyneham, 'ACT Family Violence Intervention Program review', AIC Reports Technical and Background Paper No 52, Australia Institute of Criminology, 2012; a report for the Royal Commission into Institutional Responses to Child Sexual Abuse by Bolitho and Freeman, above n 7, which assesses empirical evidence from restorative justice programs nationally and internationally, and concludes that restorative justice can be practised to good effect following sexual abuse; the findings of a UK study by Francesca Marsh and Nadia M Wager 'Restorative Justice in Cases of Sexual Violence: Exploring the Views of the Public and Survivors'(2015) 62(4) The Journal of Community and Criminal Justice Probation 336; Innovative Justice Responses to Sexual Offending Report, above n 6, recommends a program of restorative conferencing for victims of sexual offending in both civil and criminal jurisdictions, and cites program developments in New Zealand that address sexual offending and family violence cases; Shirley Jülich, John Buttle, Christine Cummins, Erin V Freeborn, Project Restore: An Exploratory Study of Restorative Justice and Sexual Violence (AUT University, 2010); K Daly, 'Reconceptualizing Sexual Victimization and Justice' in Inge Vanfraechem, Antony Pemberton and Felix Ndahinda (eds), Justice for Victims: Perspectives on Rights, Transition and Reconciliation (London, 2014) 378; the Victorian Equal Opportunity and Human Rights Commission, Independent Review into Sex Discrimination and Sexual Harassment, Including Predatory Behaviour in Victoria Police: Phase One Report (2015), recommends a Redress Scheme that is victim-centric, delivers case management, and can provide processes to address the harm caused by abuse. Neilson and Renou, above n 7, also identified that survivors consider 'restoration' as one of the key elements to their sense of justice.

15 This set of principles collate ideas from Moore, above n 4; David Moore, The Victorian Association for Restorative Justice, Royal Commission into Family Violence Submission, 2015.

16 Marc Galanter, 'Justice in Many Rooms' in M Cappelletti (ed), Access to Justice and the Welfare State (European University Institute, 1981) 147, 161-162, quoted in Access to Justice Taskforce, Attorney-General's Department, 'A Strategic Framework for Access to Justice in the Federal Civil Justice System' (Report, Access to Justice Taskforce, Attorney-General's Department, September, 2009) 3.

17 For example, the training of conference convenors has been an important focus of the DART model, and its success: see Defence Abuse Response Taskforce, Seventh Interim Report to the Attorney-General and Minister for Defence (2014) <www. defenceabusetaskforce.gov.au/reports/Documents/dart-Seventh-Interim-Report. doc>. 
This paper explores what is widely considered to have been an effective program: the Defence Abuse Response Taskforce (DART), and specifically its use of the Restorative Engagement Conference (REC) as a response to institutional abuse and sexual offending in the Australian Defence Force. It will outline DART's: (i) administrative arrangements and the REC offered to those who experienced abuse; and (ii) specifically its program of training and mentoring for all DART facilitators and participating senior Defence Force representatives. The DART program provides an example of an integrated and effective approach to working with survivors of abuse. It offers valuable lessons for programs seeking to offer appropriate justice approaches in complex matters.

The lessons from DART address some important ethical issues for practitioners and have broader applications for systems of appropriate dispute and conflict resolution and management.

\section{BRIEF BACKGROUND ON DART}

In 2011, a 'Skype incident' in the Australian Defence Force Academy triggered numerous allegations of sexual and other forms of abuse in Defence. In response to these allegations, Stephen Smith (the then Minister of Defence) with support from the then Attorney-General (Nicola Roxon) announced an external review. The Secretary of the Department of Defence commissioned law firm DLA Piper to conduct an independent review into these allegations, and to recommend further action. Between April and October 2011, DLA Piper received communications about alleged abuse from 1112 people. The Review judged as plausible the overwhelming majority of allegations of sexual or other forms of abuse by Defence personnel.

In response to the DLA Piper Review, the DART was established on 26 November 2012. It had the support of all three services. From the outset, the problem of abuse was understood to be systemic and any response needed to address the systemic problems. This understanding informed the administrative arrangements of DART.

The Taskforce aimed to: (i) provide some appropriate resolution to individual complainants; and (ii) drive cultural change within Defence. A key achievement of the Taskforce was to develop a mechanism whereby these two outcomes became mutually reinforcing: appropriate resolution for complainants drove cultural change, and evidence of cultural change supported individual recovery.

The inaugural chair of the Task Force was Len Roberts-Smith QC, former Judge of the Supreme Court of Western Australia. Roberts-Smith had a deep knowledge of Defence, and a vested interest in addressing systemic problems. He also had a rich understanding of procedural and substantive justice and a strong commitment to fostering a collaborative approach to addressing the systemic problem of abuse in Defence. He developed an innovative program by consulting widely and drawing on the expertise of a number of professions. Expert consultants in program development, trauma, and conflict management were employed throughout the 
operation of the Taskforce. In addition, the Taskforce liaised with Defence to feed lessons from the DART program into the Pathway to Change: Evolving Defence Culture program.

DART was established to assess specific complaints of sexual and other forms of abuse by Defence and to work with complainants to determine appropriate responses. It evolved through several phases. Its Terms of Reference required that it focus on individual complaints of abuse in Defence occurring before 11 April 2011, and particularly on 24 cases noted by DLA Piper from the ADF Academy. A total of 2400 complaints of abuse were received. ${ }^{18}$ An Interim Report in September 2014 stated that approximately 2000 complaints were found to be in the scope of the Taskforce's Terms of Reference. ${ }^{19}$ Any current allegations of abuse in Defence, or claims that alleged abusers were still serving, were referred to the Chief of Defence Force (CDF), for consideration of administrative or disciplinary action, or to State and Territory police, for assessment and consideration of criminal investigation or prosecution.

Many of the complaints of abuse made to the Taskforce involved allegations of serious sexual assaults. The Taskforce addressed a variety of abuse categories: sexual abuse (24 per cent of cases), physical abuse (31 per cent of cases), sexual harassment (8 per cent), or workplace harassment and bullying (37 per cent). ${ }^{20}$ Of the cases assessed, 81 per cent include a 'plausible' case of Defence mismanagement. The Taskforce applied the novel standard of 'plausibility' in accepting allegations of abuse (as sufficiently cogent to qualify for the available outcomes). ${ }^{21}$

18 People had until 31 May 2013 to register their complaint with DART. From these 2400 complaints of abuse, some cases, from women who experienced sexual abuse at Australian Defence Force Academy, being received after this cut-off date. Above n 17, 42.

19 Above n 17, 17.

20 Definitions given: (i) Sexual abuse means unwanted conduct of a sexual nature, committed against a person without their consent. It does not require physical contact between the person and the alleged abuser and can include conduct in the presence of the person; (ii) sexual harassment is unwanted and non-consensual conduct of a sexual nature; (iii) workplace harassment includes offensive, demeaning, humiliating, intimidating or threatening behaviour that is unwelcome, unsolicited, usually unreciprocated and often repeated; and (iv) bullying is a form of harassment and is repeated behaviour that does not show respect. Quoted above n 17, 43. Other important statistics: There were 72 per cent of complainants from males, 28 per cent of complainants from females, with 26 per cent of complainants from serving members and 74 per cent of complainants from those no longer serving.

21 The Defence Abuse Response Taskforce, Second Interim Report to the AttorneyGeneral and Minister for Defence (June 2013) <www.defenceabusetaskforce.gov. au/reports/Documents/dart-Second-Interim-Report.doc $>$, Appendix C provides further explanation of plausibility. Minister Stephen Smith had stipulated the standard of 'plausibility' in order that the Taskforce would provide outcomes to as many complainants as possible. There is acknowledgement, however, in the Defence Abuse Response Taskforce, Seventh Interim Report, above n 17, that the lower standard of proof has garnered negative comments from the Department of Veterans' Affairs (who has a higher standard of proof when considering complaints). 
An allegation was judged as 'plausible' if it had 'the appearance of reasonableness'. ${ }^{22}$

Only about 1 per cent of complainants wished to refer their case to the relevant policing agency. Complainants provided two main reasons for not wishing to refer their case to police: ${ }^{23}$ (i) the prospect of a successful criminal investigation was not 'good', since the alleged abuse occurred a long time ago and was never reported, and (ii) those whose allegations could be referred to police did not want to experience further trauma from a lengthy and difficult police prosecution with an uncertain outcome. ${ }^{24}$

Perhaps, more surprisingly, the DLA Piper Review found that most complainants had no particular interest in meeting directly with the identified abuser. Rather, they were deeply troubled and traumatised by the failure of Defence to administer its duty of care to its members. DLA Piper recommended a scheme of 'restorative justice', but the Taskforce considered that this term may be misleading. It may have implied that the program was a part of the formal justice system, that it had investigative powers, or that it offered hearings involving a determination of fact or law. Instead, the Taskforce proposed a 'restorative engagement conference' (REC) which was consistent with the majority of requests made by complainants. Most wanted, above all, that others would not experience similar abuse. The consistent request from complainants was to:

- have their personal account of abuse listened to by Defence;

- have their personal account accepted as true;

- be given acknowledgement that the abuse was wrong and should not have happened. ${ }^{25}$

The first Restorative Engagement Conferences were run in late 2013. After an initial pilot phase of $20 \mathrm{RECs}$, more than 40 restorative facilitators were engaged and received ongoing training to conduct conferences. When the program officially concluded in April 2016, over 700 restorative engagement conferences had been successfully facilitated. More than 300 senior Defence representatives, including CDF, the Vice Chief of the

22 Complaints to the Taskforce were required to be verified by statutory declaration. All material (including medical reports or other documentation) provided by the complainant, together with service, medical or disciplinary records obtained from Defence was reviewed. Approximately 20 per cent of allegations were rejected following assessment.

23 The Taskforce used the term 'complainant', consistent with its Terms of Reference, to describe victims of abuse who complained to the Taskforce about abuse in Defence.

24 The Taskforce will not refer any matter to police without the express consent of the complainant. However, where there is still a serving member of the Defence Force against whom allegations of abuse have been made and found plausible, the Chair will further consider whether there are any potential risks to other still serving members. If the Chair determines it necessary to refer a matter without consent, it will be referred in a way that as far as possible protects the confidentiality of the complainant.

25 Defence Abuse Response Taskforce, First Interim Report to the Attorney-General and Minister for Defence (14 March 2013) <www.defenceabusetaskforce.gov.au/ reports/Documents/dart-First-Interim-Report.doc>. 
Defence Force and the Chiefs of Army, Navy and Air Force, participated in a restorative engagement conference for people who experienced sexual and other forms of serious abuse during their military service.

In consecutive in-house evaluations of $\mathrm{REC},{ }^{26}$ complainants reported immediate therapeutic benefits and a high level of satisfaction that their concerns had been thoroughly acknowledged and addressed. ${ }^{27}$ Frequently, complainants expressed sentiments such as: 'This has given me an opportunity that I would have never got to finally confront this issue with someone that counts, and that counts more than you could imagine. ${ }^{28}$ 'The experience was huge ... a massive part of the healing process' ${ }^{29}$ or '[it was an] opportunity to make some peace with myself and help implement new changes'. ${ }^{30}$

Senior Defence representatives also reported their satisfaction in engaging in the conference. Vice Admiral Ray Griggs (AO, Chief of Navy) commented:

For senior Defence leaders it is a program that brings the darker side of Defence culture into sharp and stark relief. It reinforces and bolsters resolve to make a difference in ongoing cultural challenge programs. By picking the right leaders to participate in this program, we are ensuring senior leaders over the next decade or so will carry this experience with them. It is an experience no participant can forget. ${ }^{31}$

\section{The National DART Administrative Program}

In 2013, the Taskforce aimed to develop an innovative national administrative program, and consulted widely, drawing on the expertise of a number of professions. DART also worked in 'close consultation' with complainants. Roberts-Smith was joined on the taskforce by former head of the Attorney-General's Department Robert Cornall, former sex discrimination commissioner Susan Halliday, and the Australian Federal Police Deputy Commissioner Rudi Lammers. ${ }^{32}$

To develop the administrative framework, a consultative stage established first principles and preliminary guidelines for the program. This involved advice on the assessments and reviews of current mediation and restorative justice programs and practices, lessons from the Truth and Justice Commission in South Africa, and the responses to cases of Clergy

26 Defence Abuse Response Taskforce, Fourth Interim Report to the Attorney-General and Minister for Defence (12 December 2013) 11-13<www.defenceabusetaskforce. gov.au/reports/Documents/dart-fourth-interim-report.doc $>$.

27 Defence Abuse Response Taskforce, Seventh Interim Report, above n 17.

28 Defence Abuse Response Taskforce, Fourth Interim Report, above n 26, 13.

29 Ibid 11.

30 Ibid.

31 Defence Abuse Response Taskforce, Fifth Interim Report to the Attorney-General and Minister for Defence (March 2014) 20 <www.defenceabusetaskforce.gov.au/ reports/Documents/dart-fifth-interim-report.doc $>$.

32 The previous Sex Discrimination Commissioner, Elizabeth Broderick, was also engaged to provide advice. 
Abuse. The Taskforce group identified specific phases for implementation, so that its operations could be monitored and evaluated, and immediate adjustments made so as to improve service delivery.

The consistent 'underlying principle' in the DART program literature is 'to do no further harm'. ${ }^{33}$ A number of other important guiding principles are innovative, and unlike previous redress programs:

(1) The location: DART was considered an independent body, and so was housed not within Defence, but in the Attorney-General's Department.

(2) The creation of an evidentiary threshold of plausibility: DART effectively created a third standard of proof in determining whether or not to accept an allegation of abuse: a threshold of plausibility. ${ }^{34}$

(3) The multiple (and not mutually exclusive) avenues for redress offered to complainants: the parallel options, administered separately and not mutually exclusive, were:

(a) to pursue referral of appropriate matters to civilian police for their assessment and possible investigation and criminal prosecution;

(b) counselling: up to 10 sessions - including counselling for 'significant others' (partners, children) who may have been traumatised by the abuse;

(c) a reparation payment of up to $\$ 50,000^{35}$ (with five categories of abuse, with different levels of severity matched with specific payments, that is, from $\$ 5000$ payments up to $\$ 45,000$ with an additional $\$ 5000$ if mismanagement occurred); and

(d) the opportunity to participate in a REC which provided the complainant an opportunity to have their issues

33 Defence Abuse Response Taskforce, Seventh Interim Report, above n 17, 43. This was considered even with the method of bringing the Taskforce's responses or outcome options to the attention of possible complainants. DART was advised not to seek out individuals to register allegations of abuse but to raise awareness of the work and advertise widely.

34 Plausibility is a lower standard of proof than that applied by the Department of Defence (when considering whether to commence disciplinary or administrative sanction) or the police (in determining whether to proceed to prosecution after a police investigation where the evidentiary threshold is to consider: (i) beyond reasonable doubt, or (ii) on the balance of probabilities. A separate and well-trained group (Assessment Group) assessed individually the documentation provided by the complainant to determine whether the complaint or allegation was plausible. Where a complaint had been reviewed as not eligible, a request could be made for reconsideration with further information provided by the complainant and with a Senior Assessor or the taskforce Chair or a delegate reviewing the request.

35 Defence Abuse Response Taskforce, Seventh Interim Report, above n 17, 15. The Taskforce makes clear to complainants that Reparation Payments do not constitute an admission of liability on the part of the Commonwealth and are not paid as compensation for emotional, physical, psychological, emotional or financial loss as a result of the abuse. 
heard, acknowledged and responded to by a senior Defence representative.

(4) Well trained operational groups and supportive administrative teams:

(a) The Crime Group, which consisted of former or still-serving police officers on secondment, referred cases to civilian police agencies for possible criminal investigation;

(b) The Reparations Group, which consisted of lawyers and other staff with experience in criminal injuries or other compensation regimes, made recommendations to the independent Reparation Payments Assessor;

(c) An independent Reparation Payments Assessor made decisions on reparation payments. Although the payments were made by the Taskforce out of the Defence budget, the decisions were made outside and independently of Defence; and

(d) The Complainant Support Group (CSG) which consisted of staff with experience in counselling and victim support who provided the single point of contact for each complainant.

DART provided support to complainants throughout their interaction with the Taskforce. Initial contact with complainants was with the Complainant Liaison Team in CSG. Once their complaint was assessed by the Assessment Group, complainants were allocated a Case Coordinator in the CSG Case Coordination Team, and that Coordinator remained the complainant's personal contact throughout their time with the Taskforce. The Case Coordinators were experienced with working with people subjected to violence, discrimination, social disadvantage and trauma. The Coordinator managed information, updated on the progress of the complaint, explained processes and outcomes, and helped arrange participation in the REC. ${ }^{36}$

\section{The DART Restorative Engagement Conference (REC)}

The REC program was underpinned by the best practice principles and values of restorative practice, conciliation and mediation. It was also predicated on the application of trauma-informed care principles. ${ }^{37}$

It was understood that many abuse survivors experience Post Traumatic Stress Syndrome (PTSS), and PTSS was evident for many DART complainants. A person experiencing PTSS tends to struggle with the tension between wanting to remain silent about the trauma and wanting to speak out; as a result, they can feel out of control, unsafe and uncomfortable in a number of situations. ${ }^{38}$

$36 \quad$ Ibid 9-10.

37 Judith Hermann, Trauma and Recovery (Basic Books, 1997).

38 Ibid. 
Consistent with best practices principles, the REC program identified that its operations needed to: ${ }^{39}$

- cause no further harm to the person;

- provide safety (physical and emotional);

- foster trustworthiness (through clarity, consistency and interpersonal boundaries);

- maximise the complainant's choice and control;

- support collaboration and sharing of power;

- develop therapeutic and empowering methods to support the telling or retelling of the complainant's story (based on their wishes);

- manage a range of expectations from complainants; and

- work with Senior Defence representatives to engage and respond in a way that would not cause further harm or trauma.

In the first phase of the REC program, a group of experienced facilitators discussed with the DART team, the dynamics of the REC process. The conference was understood as essentially a truth-telling exercise. The allegation of abuse was accepted as plausible and therefore not in dispute. The typical conference could be structured to recount a specific incident of abuse, if the complainant chose to 're-tell' that experience, and a pattern of poorly resolved matters.

The working group identified that a properly facilitated conference should involve a complainant with a designated supporter - a family member - spouse, parents, or adult children or colleague, with whom they have an abiding relationship of trust. The complainant and supporter would meet with a senior Defence Representative. These meetings could achieve two key aims of the Taskforce: (i) to provide some appropriate resolution to individual complainants; and (ii) to drive cultural change within Defence.

Very experienced facilitators convened the first 20 RECs. Only the most senior Defence leaders (including the Chief of Defence, Vice CDF and the Chiefs of Army, Navy and Air Force) were chosen to participate in these conferences. Each of these senior Defence representatives had been well-briefed on the process, and had met with a consultant facilitator. These first conferences were observed by an independent and experienced evaluator (who had worked with the Truth and Reconciliation process in South Africa). ${ }^{40}$ The evaluations consisted of observations and feedback from complainants, their supporters and the Defence representatives. This feedback informed a process of fine-tuning the program's guidelines and

39 This information was obtained from personal communication with Dr David Moore, one of the two senior consultants of the Taskforce's Taskforce Restorative Engagement Group (REG). Dr David Moore was employed as a Senior External Consultant to the Taskforce's REG. The other senior member of the Taskforce's REG was Dymphna Lowry who was employed as the Special Internal Consultant. She was located at the Taskforce's offices in Canberra (and was on secondment from the Department of Justice and Community Services).

40 Professor Andrea Durbach from the University of NSW. See Defence Abuse Response Taskforce, Fifth Interim Report, above n 31. 
practices. The initial feedback from complainants was that the conference indeed provided them with an opportunity to have their personal account of abuse be heard, acknowledged and responded to by a senior representative of Defence. Complainants described the process as a highly effective means of directly addressing the harm, and the consequences of the harm.

Action learning was an ongoing feature of the REC program. An important early lesson was that the quality of the service improves when program administrators and process facilitators are all working to an agreed set of principles and engage in regular dialogue.

The first phase of the pilot program consolidated foundational skills and developed more specialist skills for training. Some examples of the lessons drawn from the pilot were: ${ }^{41}$

- The REC was best understood as a catalyst for change, and a process in its own right, and that it was a short process within the longer engagement with the DART program.

- The necessity of well-structured pre-conference sessions in building trust between the facilitator and the complainant by working with the person to craft their story about what happened and what might bring some therapeutic healing to the situation. The role of the facilitator in these sessions was to help the person to understand the nature of the process, to assist them in co-creating an agenda for the conference, and to discuss how best to manage the dialogue within the conference. This involved not only discussing what to talk about (content), but also how to talk about the matters (process). Two significant decisions for the complainant were: (i) whether they would retell the story of the abusive experience(s), or 'talk to their story'; and (ii) what types of questions they wanted to ask of the Defence representative.

- Fine-tuning the specific skills required by the facilitator not only to prepare the complainant to craft a narrative, but also to assist the complainant's supporter and the Defence representative to engage effectively in the conference. This might include, for example, preparing the Defence representative first to listen without judgement, and only later to respond effectively to the complainant.

- The importance of case managers and facilitators managing expectations about fairness with regard to both process and outcomes.

The second phase of the REC program commenced in January 2014. Forty facilitators were trained in group conferencing facilitation principles and techniques, in order to deal with the estimated 600-700 conferences scheduled to be conducted within the timeframe of DART's Terms of Reference (by the end of 2015). Although all the newly appointed REC convenors were experienced practitioners in dispute resolution, community development, law or family therapy, they were nonetheless all trained by expert facilitators in skills specific to the REC process. The convenors were supported to 'review' their methods to determine whether what was thought would

$41 \quad$ See Moore, above n 39. 
work in theory actually did work in practice. These 'reviews' took the form of facilitated group discussions, and provided further refinement for the operations of the REC program and how to run the subsequent conferences (including the pre-conference sessions).

Specialised training in the REC program's principles and techniques was also provided to the Complainant Support Group and to several hundred senior Defence representatives across Australia who would participate in the conferences.

Logistical and administrative arrangements for the conference were made by the Taskforce Restorative Engagement Group and the Defence Liaison Unit, in conjunction with Defence. In the lead-up to a referral to restorative engagement, the Case Coordinator typically canvassed a number of issues with the complainant, including explaining the purpose of the conferences.

By the time a complainant was referred to a conference, they typically had the personal support of their Case Coordinator for weeks or months. For each case, Defence nominated three representatives who met the desired criteria to participate in a conference. The Taskforce (through the relevant Case Coordinator) consulted with the complainant to select an appropriate Defence representative. The Taskforce then designated a facilitator for the conference. The facilitator's role was to conduct 'preconference sessions' with the complainant and their supporter, and with the Defence representative.

The average duration for a REC was two hours. Much of that time was taken with the complainant recounting to the Defence representative their experience and its impact. This engagement generally resulted in a collective understanding of the situation. Typically, an apology would be given by the Defence representative on behalf of the ADF, and from their current role.

When participants in a group conference develop a shared understanding, they can problem-solve. In a restorative engagement conference, this often involved discussing reforms that have happened in the ADF and making plans if necessary. They could include some form of practical or symbolic action that may support the complainant to recover, and some articulation of how the Defence could make use of the lessons from the conference.

A minority of conferences were conducted as 'indirect' engagements, with the complaint and Defence representative actually not meeting face to face. Instead, the facilitator relayed additional elements of the complainant's account to the Defence representative, and negotiated some form of formal gesture, most typically a letter of apology.

One of the most outstanding achievements of the RECs has been the therapeutic effect for complainants. ${ }^{42}$ Facilitators worked with the

42 The comments and observations that follow are from personal communication with David Moore in relation to the induction training for Defence Representatives involved with the DART Restorative Engagement Conference program. Dymphna Lowry and David Moore also presented their reflections on 
complainant to help them deliver 'a sufficiently detailed and coherent narrative of events and their aftermath'. This exercise seems to have provided the emotional distance required to gain a new perspective about the abuse. Those affected reported having 'new insights into the significance of event(s) and their aftermath, and were able to 'let it go' and 'move on'. This shift and realignment of thoughts and feelings seems to have occurred because the complainant had the opportunity to tell their story to a person who mattered to them, and who had authority to 'do something' with any lessons. ${ }^{43}$ Telling one's story to someone who can do something with its lessons means that the affected person can let go of it. The conference process seems to have supported post-traumatic growth for complainants.

\section{A REC Facilitators' Skills}

A Facilitator's Handbook, prepared by Dr David Moore ${ }^{44}$ and Taskforce colleagues, provided step-by-step guidelines not only on what to do administratively in a typical REC but also on how to facilitate by applying the principles that can best minimise and manage unexpected developments.

The Facilitators' Handbook outlined a number of (interrelated) principles to guide the program administration and the techniques adopted by the facilitators convening the conference process. Guiding principles included:

(1) Do no further harm: this principle placed particular emphasis on establishing methods to foster fairness and care.

(2) Risk management: this principle seeks to avoid the risk of complainants being used as a means to the end of reforming the organisational culture of the ADF. The focus is to ensure that a therapeutic outcome for complainants and their supporter(s) is an end in itself (that is, their own need for psychological well-being is an end) and is not perceived as secondary to reforming the governance and workplace culture of the Defence Forces. This principle supports the first principle of no further harm.

To support the therapeutic effects for complainants throughout their engagement, the following principles need to be realised:

(3) Acknowledgement: the basic truthfulness of the complainant's account, their experience, and the subsequent impact on their life is to be recognised and accepted by the ADF. Their account is not in dispute. This acknowledgement extends to the DART program itself and its unequivocal support of the rights and recovery of the complainants.

the training at the Restorative Practices International Conference 'Building Restorative Communities' (Hotel Grand Chancellor, Hobart, March 2015).

43 Ibid.

44 See Moore, 'Managing Social Conflict', above n 4; See also Moore, 'The Victorian Association for Restorative Justice', above n 15. 
(4) Readiness: this principle encourages facilitators (and complainant support staff) to work with the complainant to identify and increase their readiness to participate; and

(5) Equal clarity, transparency and respect for all involved is realised through effective discussion about what the REC process is. Engaging in a respectfully clear and transparent way also increases the sense of control, safety and comfort experienced by the complainant and the other participants.

The Handbook emphasised other key elements of the REC aims and features:

- the complainant's account of the abuse and the resultant harm is accepted and not in dispute;

- Defence accepts that the abuse was wrong, and that Defence have a responsibility to respond;

- the focus is on the complainant's needs - the primary aim is to provide a beneficial experience for the complainant;

- the complainant is not required to waive their right to take any legal or other action;

- there is no discussion about money;

- the complainant is not required to sign any confidentiality agreement that would prevent them talking about the abuse they suffered;

- the complainant's confidentiality is absolute and what occurs in the conference itself is confidential to those present, and to the Taskforce.

\section{Some Lessons FRom DART}

The DART program is an example of an appropriate justice approach to institutional abuse. It offered a number of processes to survivors of abuse, worked with them to determine an appropriate response, and was developed over a number of phases in consultation with legal, health and human service agencies and expert practitioners.

The DART administrators clearly distinguished the program requirements from the various processes offered. They also established a set of principles that applied across its service delivery. A case management approach provided complainants a range of processes. The administrative arrangement was informed by analysis of other programs, which highlighted that related but separate processes work best when they are 'quarantined' from each other, and offered as a suite of distinct (and parallel) options. For instance, the REC could focus on giving the complainant a voice, validation of their experience, and vindication regarding their claims, without having to also consider reparation. Each of the administrative personnel had the requisite skills for operations in their specific area. The 'built in' ongoing training and review mechanisms provided targeted training, mentoring and monitoring for facilitators, administrative staff and others involved in the program's delivery. 
More specifically, the REC program designers drew on key lessons from the last twenty five years of restorative practices to modify the group conferencing process according to the requirements of the DART program. There is a generic conferencing process. The group conferencing process is structured to ask and engage specific questions: 'What has happened? How have people been affected? What can be done to improve the situation? In other words: how can harm be healed and further harm prevented?' However, this generic process needs to be varied to accommodate the types of case involved in the program in which the conferencing process is used.

In conventional justice system settings, the group conference process is used to respond to incidents of undisputed harm. ${ }^{45} \mathrm{In}$ youth and adult justice system programs, there is no dispute about who committed the crime, but there is a great deal of conflict within people, between people, and between groups as a result of what happened. The conference provides a mechanism for dealing effectively with the harm that can be both a cause and a consequence of criminal behaviour. However, group conferencing is also applicable not only to any single incident of undisputed harm, but also as a response to conflict associated with a pattern of many poorly resolved incidents and issues. ${ }^{46}$

In the search for more effective systemic responses to sexual offending and family violence, the use of group conferencing has been adapted and is co-evolving to deal with, for example, historical and intra-familial cases, and for planning in cases where there is separation. ${ }^{47}$ Any program that seeks therapeutic or restorative outcomes to institutional abuse, sexual offending and family violence through group conferencing must answer a number of questions such as the types of cases the program will accept, the system of case management, when it is offered, what format the conferencing process should take, who will be involved, and how the program is to be continually monitored..$^{48}$

The DART program responded to the pressing concern of survivors of abuse. And in nearly all of these cases, that concern was not to meet with

$45 \quad$ See Heather Strang, Lawrence W Sherman, Evan Mayo, Daniel Woods, Barak Ariel, 'Restorative Justice Conferencing (RJC), Using Face-to-Face Meetings of Offenders and Victims: Effects on Offender Recidivism and Victim Satisfaction. A Systematic Review' (2013) 9(12) Campbell Systematic Reviews 1.

46 See Moore, 'The Victorian Association for Restorative Justice', above n 15.

47 See Kathy Daly, Gitana Proietti-Scifoni, 'Gendered Violence and Restorative Justice: The Views of New Zealand Opinion Leaders; University of Canterbury', Selecting Interventions to Reduce Family Violence and Child Abuse in New Zealand: A Report to the Glenn Inquiry (September, 2014) <www.noviolence. com.au/sites/default/files/reportfiles/selectinginterventions.pdf $>$; Lisanne Drost, Birgitt Haller, Veronika Hofinger, Tinka van der Kooij, Katinka Lünnemann, Annemieke Wolthuis, Restorative Justice in Cases of Domestic Violence: Best Practice Examples Between Increasing Mutual Understanding and Awareness of Specific Protection Needs (IARS International Institute, 15 October 2015) <iars.org.uk/sites/default/files/Comparative\%20report\%20II\%20 final.pdf>

48 Moore, 'The Victorian Association for Restorative Justice', above n 15; Centre for Innovative Justice, above n 6. 
the perpetrator. Rather, they wished to meet with senior ADF representatives who could address the institution's failure in its duty of care. The REC program also provided: (i) a safe and supportive environment; (ii) the right forum for survivors to craft how they wanted to tell the story of what has happened, its impact and, to consider, what could be done about it with the right person; and (iii) therapeutic benefits on multiple levels for survivors and other conference participants due to the care and consideration given to the impact of trauma and to conflict.

The training of conference facilitators was also an important focus of the DART model, and a factor contributing to its success. ${ }^{49}$ Action learning forums were used to identify the specific competencies for facilitators. These forums established an alignment between: (i) best practice facilitation techniques; (ii) feedback from participants about what had worked; and (iii) observations and insights from the facilitators. Ongoing coaching, mentoring and observations reinforced consistency of practice and sought to maintain process integrity.

Evaluations of other restorative engagement programs have emphasised the specialist skills, knowledge and experience of the facilitator, as a significant condition for the success of a conference, and in it achieving therapeutic and appropriate outcomes. ${ }^{50}$ However, program administrators must support the development and transfer of these skills. For instance, although DART facilitators may have faced individual ethical challenges, these were best addressed as part of the adminstration of the REC program. This is a useful lesson for other dispute and conflict resolution practitioners.

In a recent evaluation of mediation, ${ }^{51}$ the authors highlighted some potential and real ethical challenges faced by mediators. It was suggested that 'despite ... a common set of standards and the agreed critical value of self-determination in mediation, mediators have varying moral compasses that lead to a variety of responses to ethical and practical challenges'. The case studies in this evaluation highlight differences between a good outcome and a just outcome, between procedural and substantive fairness, and to the "just distribution of the burdens and benefits of social cooperation'. These differences relate not solely to the decisions faced by individual mediators, but: (i) to the legal system as a whole; and (ii) the set of process options available in the search for a just resolution of disputes and conflicts. The reliance on individual practitioner's moral compasses alone is not desirable. The variety of mediators' responses to different case scenarios, may be due, in part, to variation in the level of understanding and skill of the practitioner, the working definition of 'mediator', and the administrative program or context in which the mediation operates. Some of the ethical issues can be loosely categorised as problems relating to:

49 Defence Abuse Response Taskforce, Seventh Interim Report, above n 17.

50 Bolitho and Freeman, above n 7, 8-14.

51 Mary Anne Noone and Lola Akin Ojelabi, 'Ethical Challenges for Mediators around the Globe: An Australian Perspective' (2014) 45 Journal of Law \& Policy 144. 
(i) programs that mandate mediation; and (ii) the mediation process as currently practised. Many questions about programs and process are best understood less as ethical challenges for individual mediators and more as ethical challenges for the profession of $\mathrm{ADR}$ and for the administration of civil and criminal law.

As Judge Harman states, 'mediation has a fundamental role and value in the proper administration of both justice and society. However, when it is seen in isolation from the system of which it is part ... it is mischaracterised'. ${ }^{52}$ Similarly, if the program administration through which a process is offered, or the legislation that governs its operation is not adequately considered, then the evaluation of the practitioners' effectiveness may also be mischaracterised. ${ }^{53}$

The DART program was only available to people who experienced abuse while serving with the Australian Defence Forces. However, the lessons we can draw from DART have far wider implications, and have already provided some guidance for how to design and improve appropriate justice approaches and mechanisms in family violence and child sexual abuse. Broader ethical questions, such as 'How can we ensure fair play?' and 'How can we generate fair outcomes?', were addressed in consultation with legal, health and human service agencies and expert ADR and conflict management practitioners, and with those affected by the abuse.

\section{Concluding Comments}

Access to appropriate justice mechanisms involves ensuring the law and its administration is fair and just - this includes ensuring that our systems for addressing social harm, legal and social problems all foster fair play and fair rules. This concept goes beyond considering just procedural rights and includes substantive rights and interests so that the law and processes that deal with problems are not just about treating everyone the same but are, in effect, treating people fairly and problems effectively. This involves considering which process option (or series of process options) is most likely to produce an appropriate and fair resolution of the presenting issues. Implementing processes that can both respond more effectively to adverse conditions and problems as well as to minimise or mitigate such risk factors are clearly some of the aims of justice.

Improving dispute and conflict resolution and management systems requires: (i) a set of principles that can apply across a variety of situations and processes; (ii) a broader view of justice and governance which involves fostering collaboration among social agencies, the State, judiciary, and community groups; and (iii) ‘built in' ongoing review mechanisms in

52 Harman, above n 2, 18-19.

53 Chief Justice Bathurst comments on the circumstances in which mediation is considered appropriate but also on how to ensure efficient case management of cases. See Bathurst, above n $3,877$. 
program administration which involve reflective and progressive problem solving to address issues and adjust service delivery, and to support a 'community of practice' who can collectively develop and increase their skills through a culture of reflective practice.

The DART program demonstrated how a series of ethical issues were addressed by developing a set of principles that applied across its service delivery. Such issues were not left to the moral compass of the individual practitioners, but were best addressed as part of the adminstration of the restoratve engagement conferencing program. In addition, the facilitators' training and ongoing reviews provided the structural support to deal with ethical challenges consistently and effectively. 